\title{
The Competitive NMDA Receptor Antagonist CPPene Stimulates NREM Sleep and Eating in Rats
}

\author{
Ian Glenn Campbell, Ph.D., Lorell Marie Gustafson, B.S., and Irwin Feinberg, M.D.
}

Systemic administration of noncompetitive NMDA receptor antagonists, such as MK-801, produces a period of intoxication followed by non- rapid eye movement (NREM) sleep with greatly elevated delta EEG activity. We have hypothesized that the delayed NREM delta EEG increase is a homeostatic response to the immediate elevated limbic metabolism that these drugs produce. Here we test this hypothesis by examining the sleep and EEG effects of CPPene, a competitive NMDA antagonist that does not elevate limbic metabolism. We recorded EEG in seven rats following mid-dark period systemic injections of saline and three doses of CPPene. CPPene did not produce the delayed NREM delta increase. Instead, CPPene increased eating time and dose dependently increased NREM sleep duration shortly after injection. These differences in sleep EEG response to a competitive versus the noncompetitive NMDA antagonists are consistent with the possibility that the increased NREM delta following noncompetitive antagonists is a homeostatic response to increased limbic metabolism.

[Neuropsychopharmacology 26:348-357, 2002] (C) 2002 American College of Neuropsychopharmacology. Published by Elsevier Science Inc.

\section{KEY WORDS: Sleep; EEG; Glutamate; NMDA}

There is increasing evidence that excitatory amino acids play a role in the regulation of sleep. Our own studies have focused on perturbations of the $\mathrm{N}$-methyl-D-aspartate (NMDA) receptor. These studies initially aimed to test the hypothesis that the increase in limbic metabolism stimulated by noncompetitive NMDA receptor antagonists would increase the intensity of delta (1-4 $\mathrm{Hz}$ ) electroencephalograph (EEG) in subsequent nonrapid eye movement (NREM) sleep (Feinberg and

From the Veterans Administration Northern California Health Care System and the Department of Psychiatry, University of California, Davis.

Online publication: 9/4/01 at www.acnp.org/citations/ Npp090401172

Address correspondence to: Ian Campbell, VA/UCD Sleep Lab TB148, University of California Davis, CA 95616, Tel.: (530) 7527216, E-mail: igcampbell@ ucdavis.edu

Received April 5, 2001; revised July 16, 2001; accepted August 27, 2001.
Campbell 1993). Current homeostatic models of slow wave sleep propose that NREM sleep serves a recuperative function for the brain and that the intensity of slow wave (delta) EEG reflects the intensity of the recuperation (Feinberg 1974; Borbely 1982). According to one model, the homeostatic requirement is a function of both waking duration and the metabolic rate of plastic brain structures during waking (Feinberg 1974). Noncompetitive NMDA antagonists such as ketamine and MK-801 stimulate limbic system metabolic rate particularly in the hippocampus, cingulate cortex, and entorhinal cortex (Nelson et al. 1980; Crosby et al. 1982; Hammer and Herkenham 1983; Kurumaji et al. 1989). Our homeostatic model predicts that stimulation of these plastic structures should increase NREM delta.

Our initial studies used the noncompetitive NMDA antagonists ketamine and MK-801 to increase metabolic rate in limbic structures. Subanesthetic doses of ketamine or MK-801 injected in rats during the dark (waking) period produced a period of intoxication followed by greatly ele- 
vated delta EEG intensity in subsequent NREM sleep (Feinberg and Campbell 1993; Campbell and Feinberg 1996a). The NREM delta stimulation was dose dependent for both ketamine and MK-801 (Feinberg and Campbell 1995; Campbell and Feinberg 1996a). This NREM delta increase is as great as or greater than that produced by any other pharmacologic agent. Because delta waves can be a manifestation of brain dysfunction, we also performed a series of experiments to rule out the possibility that the increased delta following noncompetitive NMDA antagonists was caused by the toxic effects that these drugs can produce (Campbell and Feinberg 1996b).

CPPene (DL (E)-4-(3-phosphonoprop-2-enyl)piperazine-2-carboxylic acid) is a competitive NMDA antagonist that shares several properties (e.g. anticonvulsant, antiexcitotoxic) with noncompetitive antagonists. However, CPPene does not increase limbic metabolism when injected systemically (Boddeke et al. 1992). Therefore, according to the homeostatic model CPPene should not increase the need for NREM delta. We tested this hypothesis by administering CPPene systemically, at the same hour of the dark period as in the MK- 801 study, and comparing vigilance state and EEG responses to those following saline injection.

\section{METHODS}

\section{Subjects}

Seven male Sprague-Dawley rats were used in the CPPene dose response study. Nine additional animals were used in a pilot study to establish the dose range, and four more were used to examine blood pressure effects. All rats were approximately 300 grams at the time of surgery. Under deep pentobarbital anesthesia (65 $\mathrm{mg} / \mathrm{kg}$ ), rats were implanted with flexible wire EMG electrodes in the nuchal muscles, a stainless steel screw ground electrode over the olfactory bulb, and six cortical screw electrodes over the frontal, frontoparietal and parietal cortices at the following coordinates $(\mathrm{mm})$ relative to bregma: Anterior Posterior (AP) +4.5, Lateral (L) +2.5; $\mathrm{AP}+1.5, \mathrm{~L}+3.5 ; \mathrm{AP}-1.5, \mathrm{~L}+2.5 ; \mathrm{AP}-4.5, \mathrm{~L}+3.5$; $\mathrm{AP}+1.5, \mathrm{~L}-3.5 ; \mathrm{AP}-1.5, \mathrm{~L}-2.5$. Leads from the electrodes were inserted into a small connector cemented to the rat's skull with dental acrylic.

After a 2-wk recovery period, rats were trained to the recording apparatus, a commutator and cable counterbalanced to allow free movement around the cage. During training, EEG was recorded from all possible ipsilateral pairs of electrodes, and the three cleanest signals were selected for recording in the experiment. The best of these three signals was used for EEG analysis. All recordings were made with the rats in their home cage in a temperature $\left(20-22^{\circ} \mathrm{C}\right)$ and light $(12: 12)$ controlled room. Recordings were $24 \mathrm{~h}$ in duration and began at the start of the dark period.
To simultaneously measure EEG and blood pressure effects of CPPene, four rats were implanted, two weeks after electrode implantation, with an indwelling carotid cannula filled with heparinized saline. Surgery was again carried out under deep pentobarbital anesthesia. Cannulas were flushed daily with heparinized saline. Rats in the blood pressure study were habituated to restrainers in the period between the electrode and cannula implant surgeries.

The UC Davis Animal Use and Care Advisory Committee approved all procedures.

\section{Experiment Design}

Each recording session consisted of four consecutive 24-h periods. The first was a habituation period with no recording, the second a 24-h control recording with saline $(0.5 \mathrm{ml} / \mathrm{kg})$ injected intraperitoneally (i.p.) at hour 6 of the dark period, the third a 24-h recording with CPPene $(0.5 \mathrm{ml} / \mathrm{kg})$ injected i.p. at hour 6 of the dark period, and the fourth a 24 -h recovery day recording with no injections. CPPene, generously provided by Sandoz Pharmaceuticals, was dissolved in saline $15 \mathrm{~min}$ prior to injection. Injections were made in the dark under dim red illumination. In the dose response study each rat was injected with $0.625,1.25$, and $2.5 \mathrm{mg} / \mathrm{kg}$ doses with at least 1 week separating drug doses. Dose order was counterbalanced and rats were randomly assigned to a dose order. Rats were observed for behavioral abnormalities from the time of injection until behavior returned to normal. Particular attention was paid to posture and coordination during walking and rearing. We conducted no tests requiring intervention such as righting reflex or rotorod assessment because these would interfere with sleep responses. Time spent eating was estimated by the number of epochs containing the high frequency $(>80$ $\mathrm{Hz}$ ) artifacts that we previously found were associated with eating. Because the behavioral changes (see below) induced by 1.25 and $2.5 \mathrm{mg} / \mathrm{kg}$ doses were obvious, missed i.p. injections (one at $1.25 \mathrm{mg} / \mathrm{kg}$ and one at $2.5 \mathrm{mg} / \mathrm{kg}$ in separate rats) were readily apparent. Data from the two missed injections were discarded prior to evaluating the sleep or EEG responses, and these two treatments were repeated in subsequent recording sessions. The missed injections disrupted the counterbalance of injection order, but we found no difference (within one standard deviation of the mean) in rats with missed injections.

To determine whether decreased blood pressure might have produced the CPPene induced EEG changes through decreased cerebral perfusion, blood pressure and EEG were simultaneously recorded in two rats implanted with a carotid cannula. Four rats had been implanted, but clogged cannulas prevented blood pressure recording in two. EEG and BP were recorded 
from restrained rats for approximately $1 \mathrm{~h}$ prior to and $5 \mathrm{~h}$ post i.p. injection of $2.5 \mathrm{mg} / \mathrm{kg}$ CPPene. Cannulas were flushed during recording if pulse pressure dropped abruptly.

\section{EEG Recording and Analysis}

EEG and EMG signals were amplified and filtered with Grass 7P511 amplifiers. Filter settings were $0.3 \mathrm{~Hz}$ low, $100 \mathrm{~Hz}$ high for EEG and $3 \mathrm{~Hz}$ low and $500 \mathrm{~Hz}$ high for EMG. $60 \mathrm{~Hz}$ notch filters were not used on any recording. PASS PLUS (Delta software, St. Louis) digitized the amplified signals at $256 \mathrm{~Hz}$ and performed online period amplitude and spectral analyses. A $200 \mu \mathrm{V} 10 \mathrm{~Hz}$ sine wave calibrated PASS PLUS before each recording session. FFT windows were $4 \mathrm{~s}$ Welch tapered windows with $2 \mathrm{~s}$ overlap, yielding five windows per $10 \mathrm{~s}$ epoch. FFT frequencies in these analyses differed slightly from integer values; delta was $1.25-4.25 \mathrm{~Hz}$ rather than $1-4$ $\mathrm{Hz}$. For simplicity, integer values are used to describe frequency bands in the remainder of this manuscript. Frequency bands were $1 \mathrm{~Hz}$ wide for $1-4 \mathrm{~Hz}, 2 \mathrm{~Hz}$ wide for $4-12 \mathrm{~Hz}, 12-15 \mathrm{~Hz}, 5 \mathrm{~Hz}$ wide for $15-35 \mathrm{~Hz}$, and $35-$ $50 \mathrm{~Hz}$. For statistical analyses, these bands were collapsed into the following a priori determined bands: 1-4, 4-6, 6-10, 10-20, 20-30, and 30-50 Hz.

Each $10 \mathrm{~s}$ epoch was visually scored as NREM, REM or wake using an onscreen display of the digitized data with access to plots of period amplitude analyzed wide band EMG and FFT analyzed delta EEG and rho band EEG (25-30 or 30-35 Hz depending on the animal). Rho is an indicator of REM sleep (Campbell and Feinberg 1993). A second scorer checked all scoring. Epochs containing artifacts (low frequency movement artifacts and high frequency eating artifacts) were excluded from EEG analysis but included in the state durations. The scoring and EEG databases were then linked and FFT power was summed for each frequency band for each state for each hour. Since EEG amplitude varies between rats, FFT power in each frequency band in each vigilance state in each hour was divided by 24-h saline power totaled across $1-128 \mathrm{~Hz}$ in all states in all artifact free epochs. Both total power and power per min of vigilance state were determined.

Period amplitude analysis results are reported for the frequency bands showing the greatest difference between drug and saline FFT power. For frequencies below $10 \mathrm{~Hz}$, half waves were identified by baseline crossings. Above $10 \mathrm{~Hz}$, half waves were defined by successive zero first derivatives (peak-trough). Period amplitude analysis allows separate measurement of wave incidence and amplitude. Incidence is reported as time in frequency band (TIB) per epoch. Amplitude is average sample amplitude (ASA). Integrated amplitude (IAM), the product of ASA and TIB, is the period amplitude measure analogous to FFT power.

\section{Statistical Analysis}

Except for vigilance state durations, all data were standardized prior to statistical analyses. Data were collapsed into frequency bands as described above and analyzed in 6-h blocks. We used paired $t$-tests to evaluate differences between saline data and data for corresponding 6-h blocks on drug and recovery days. Because of the large number of tests we set $\alpha$ at 0.01 . For all variables where more than one dose induced significant differences from saline, we evaluated the dose dependence of the differences with a repeated measures ANOVA for dose with saline values as a covariate (BMDP 2V: Dixon et al. 1990) followed by Tukey's multiple comparison test to determine which doses differed.

\section{RESULTS}

\section{CPPene Dose Response (0.625 -2.5 mg/kg)}

Behavioral Observations. Both 1.25 and $2.5 \mathrm{mg} / \mathrm{kg}$ induced mild ataxia, with swaying or falling when rearing. Both doses greatly increased estimated eating time and time spent lying down, confirmed as increased sleep in the EEG analysis. Figure 1 compares eating time, as estimated by number of $10 \mathrm{~s}$ epochs with eating artifacts, following saline and $2.5 \mathrm{mg} / \mathrm{kg}$ CPPene injection. Estimated eating time increased over $200 \%$ in the first hour then dropped below saline values in the second and third hour post drug during the period that sleeping time was greatly elevated. Eating and sleeping

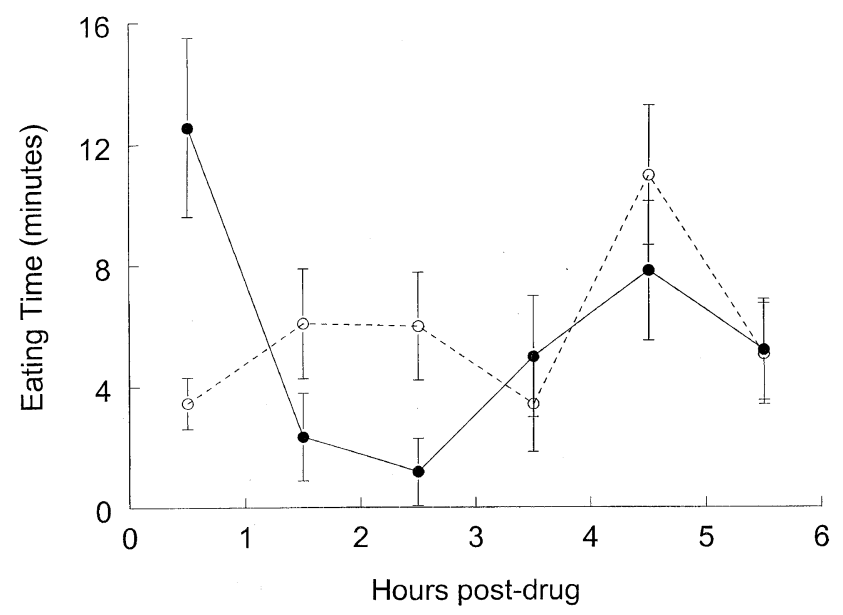

Figure 1. Mean ( \pm s.e.) estimated eating time in post injection hours 1-6 (dark period hours 7-12) following saline (open circles, dotted line) and $2.5 \mathrm{mg} / \mathrm{kg}$ CPPene (filled circles, solid line). Eating time was estimated by the number of $10 \mathrm{~s}$ epochs containing eating associated high frequency artifacts. In the first hour following CPPene injection, estimated eating time increased by more than $200 \%$ over saline levels. In the next two hours, estimated eating time decreased in association with increased sleep time. 
Table 1. Effect of CPPene on Mean ( \pm s.e.) Vigilance State Durations in Hour 7-12 of the Dark Period in Rats $(\mathrm{n}=7)$ Injected with Saline or Drug at Hour 6

\begin{tabular}{|c|c|c|c|c|c|c|}
\hline \multirow[b]{2}{*}{ Dose (mg/kg) } & \multicolumn{2}{|c|}{ NREM min } & \multicolumn{2}{|c|}{ REM min } & \multicolumn{2}{|c|}{ Wake min } \\
\hline & Saline & CPPene & Saline & CPPene & Saline & CPPene \\
\hline 0.625 & $137.7(8.0)$ & $131.1(12.1)$ & $18.1(2.1)$ & $19.0(2.4)$ & $200.4(8.8)$ & $206(12.6)$ \\
\hline 1.25 & $131.9(6.1)$ & $149.9 *(4.6)$ & $18.5(1.7)$ & $25.6^{+}(2.3)$ & $205.6(8.1)$ & $181.6^{*}(6.5)$ \\
\hline 2.5 & $128.3(4.6)$ & $167.5^{*}(4.2)$ & $15.4(1.6)$ & $22.6^{+}(2.7)$ & $213(5.1)$ & $167^{*}(6.3)$ \\
\hline
\end{tabular}

* Differs from saline at $\alpha=0.01$

${ }^{\dagger}$ Differs from saline at $\alpha=0.05$

drives appeared to compete, as rats often fell asleep beneath the food bin, woke up to eat, then slept again. The $0.625 \mathrm{mg} / \mathrm{kg}$ dose induced no behavioral changes.

Vigilance State Effects. As shown in Table 1, in the 6-h post drug, mean NREM duration increased $31 \%$ following $2.5 \mathrm{mg} / \mathrm{kg}$ CPPene and $14 \%$ following $1.25 \mathrm{mg} /$ $\mathrm{kg}$ CPPene; $0.625 \mathrm{mg} / \mathrm{kg}$ did not affect NREM duration. Figure 2 shows that NREM duration increased primarily in hours 2, 3 and 5 post drug. A comparison of the three doses revealed a significant dose response $\left(\mathrm{F}_{2,11}=\right.$ $7.81, p=.008)$ for the NREM increase; however the 2.5 $\mathrm{mg} / \mathrm{kg}$ increase in NREM was not significantly greater than the $1.25 \mathrm{mg} / \mathrm{kg}$ increase. NREM duration returned to saline levels in the subsequent light period. The REM duration increase shown in Table 1 did not reach the a priori level of significance for either $1.25(\mathrm{t}=3.27, p=$ $.017)$ or $2.5(\mathrm{t}=2.53, p=.044) \mathrm{mg} / \mathrm{kg}$ CPPene. However, this strong trend would reach likely significance with additional animals. Power analysis with $1-\beta=$ 0.8 and $\alpha=0.01$ shows that one additional animal at $1.25 \mathrm{mg} / \mathrm{kg}$ and five additional animals at $2.5 \mathrm{mg} / \mathrm{kg}$ would be needed. Waking duration significantly decreased in the six hours post drug as a result of the elevated NREM and REM levels. All CPPene induced changes in vigilance state were limited to the first $6 \mathrm{~h}$ post drug (hours 7-12 of the dark period). There were no rebounds or compensations in the subsequent $36 \mathrm{~h}$.

State Specific EEG Effects. Overall, the EEG was not greatly altered by CPPene. Figure 3 shows the NREM, REM and wake power spectra for hours $1-6 \mathrm{~h}$ post saline and $2.5 \mathrm{mg} / \mathrm{kg}$ CPPene. The largest changes were decreased NREM 4-10 Hz power/min, increased REM 20-30 Hz power/min and decreased waking 10-20 Hz power/min.

Total NREM delta power increased significantly $(\mathrm{t}=$ $6.59, p=.0006)$ in the first $6 \mathrm{~h}$ following $2.5 \mathrm{mg} / \mathrm{kg}$ CPPene (Figure 2, Panel D). This increase was due to the increased NREM duration; the rate of delta production (power/min) did not change. Within the 1-4 $\mathrm{Hz}$ delta band, $2.5 \mathrm{mg} / \mathrm{kg}$ CPPene increased 1-2 Hz, and decreased 3-4 Hz. There was a slight non-significant increase in total NREM delta power across the light period (6-18 $\mathrm{h}$ post injection). Total NREM delta was unaffected by $1.25 \mathrm{mg} / \mathrm{kg}$ CPPene. Decreased delta power/min (Figure 4) offset the increased NREM duration.

As seen in Figure 4, both 1.25 and $2.5 \mathrm{mg} / \mathrm{kg}$ CPPene decreased NREM 4-10 Hz power/min in the first six hours post drug. The decreases in both $4-6$ and $6-10 \mathrm{~Hz}$ power $/$ min were significantly dose dependent $\left(\mathrm{F}_{2,11}=\right.$ $4.15, p=.045$ and $\mathrm{F}_{2,11}=4.67, p=.034$ ). Only the effects of the 2.5 and 0.625 doses differed significantly. In high frequencies, NREM power/min showed a delayed (7$24 \mathrm{~h}$ post drug) increase following the $2.5 \mathrm{mg} / \mathrm{kg}$ dose.

We used period amplitude analysis to evaluate the contributions of changes in wave incidence and amplitude to the changes in spectral power. For $2.5 \mathrm{mg} / \mathrm{kg}$ in the first six hours post drug, the $19 \pm 3 \%$ mean ( \pm s.e.) decrease in $4-10 \mathrm{~Hz}$ power/min corresponded to a $13 \pm 3 \%$ decrease in integrated amplitude per min. This

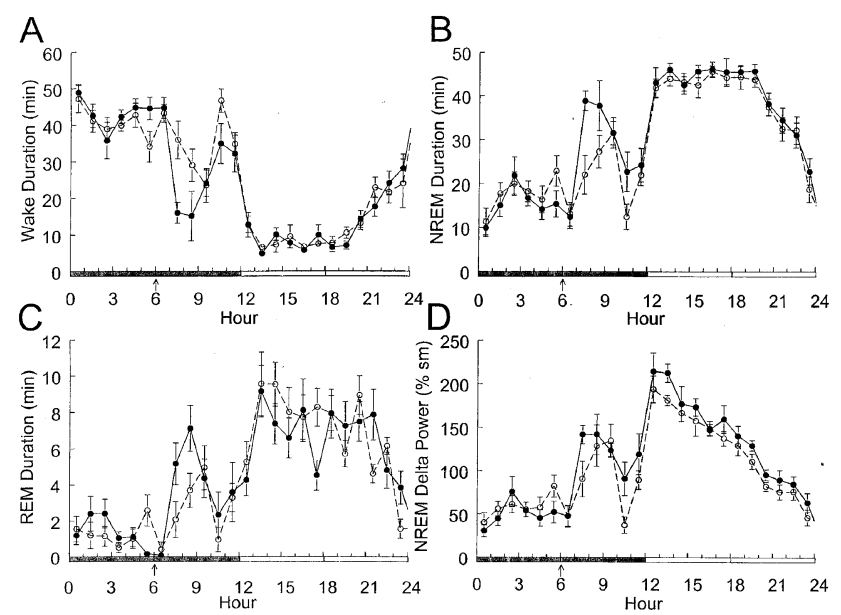

Figure 2. Vigilance states and total NREM delta following saline (open circles, dotted line) and $2.5 \mathrm{mg} / \mathrm{kg}$ CPPene (filled circles, solid line). Arrows indicate injection time. In the last six hours of the dark period CPPene significantly decreased waking duration (Panel A), significantly increased NREM duration (Panel B), and increased REM duration (Panel C). Mid-dark period CPPene injection did not affect light period vigilance state durations. Total NREM delta power (Panel D) increased in parallel with NREM duration in the dark period. It was slightly but not significantly elevated across the light period. 

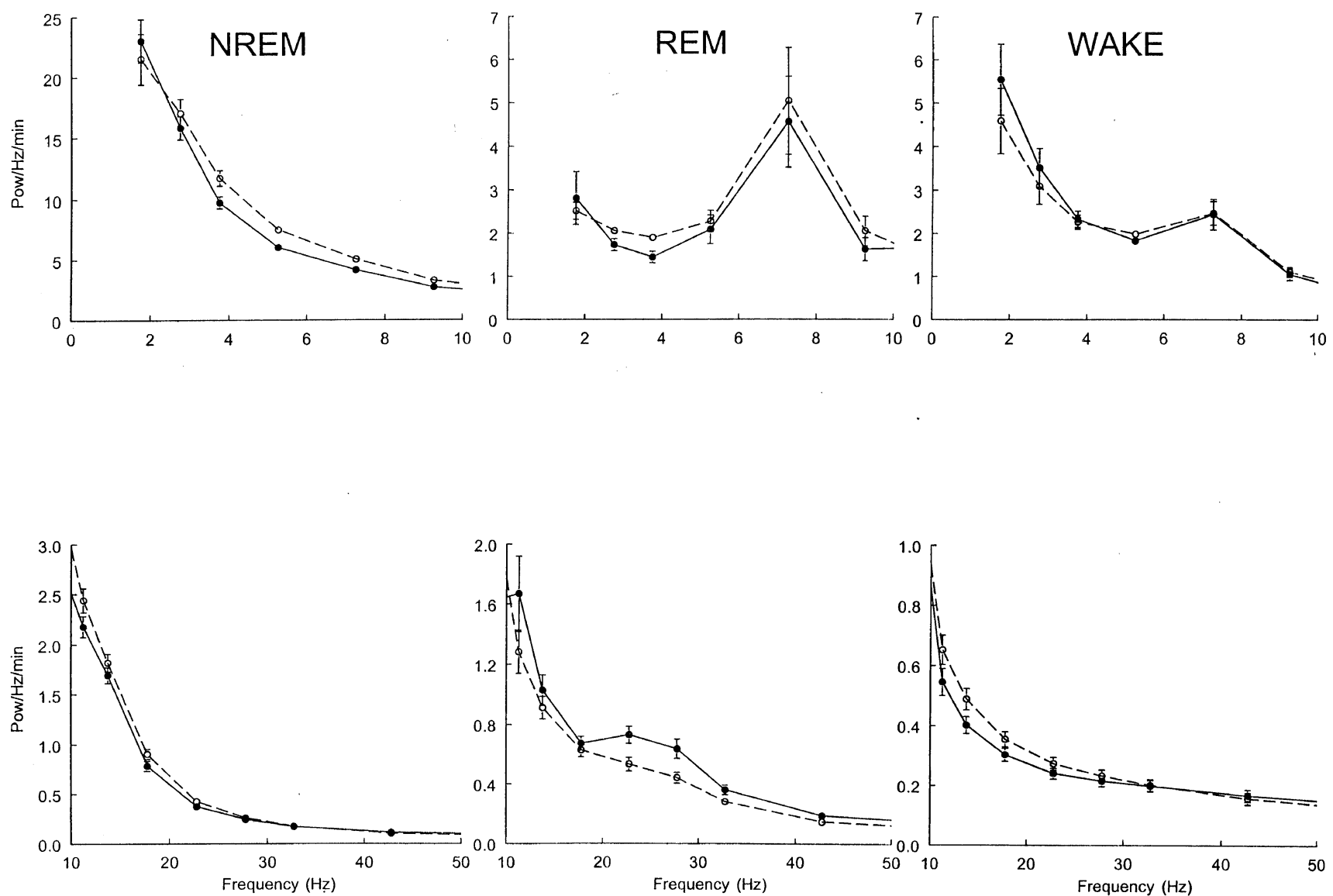

Figure 3. Power density (pow/Hz/min) spectra for NREM, REM, and Wake. Data have been standardized for each rat by expressing $1000 \times$ pow $/ \mathrm{Hz} / \mathrm{min}$ as a percent of the saline day $24-\mathrm{h}$ total power in $0.3-128 \mathrm{~Hz}$ in all vigilance states. Mean ( \pm s.e., $\mathrm{n}=7$ ) data displayed are for the first six hours following mid dark period injection of saline (open circles, dotted line) and $2.5 \mathrm{mg} / \mathrm{kg}$ CPPene (filled circles, solid line). Note the different Y-axis scales for the different vigilance states and high and low frequencies. CPPene depressed NREM 4-20 Hz EEG power, increased >20 Hz REM EEG power, and decreased 10$20 \mathrm{~Hz}$ wake EEG power.

decrease in 4-10 $\mathrm{Hz}$ activity resulted primarily from the $11 \pm 3 \%$ decrease in incidence with only a $3 \pm 1 \%$ decrease in amplitude.

In REM sleep, all three CPPene doses increased high frequency power/min. As seen in Figure 4, the magnitude and duration of the elevation increased with increasing doses. The largest effect, up to a $42 \%$ increase following $2.5 \mathrm{mg} / \mathrm{kg}$, for all doses was in the $20-30 \mathrm{~Hz}$ band in the first six hours post drug. This increase in power $/ \mathrm{min}$ was dose dependent $\left(\mathrm{F}_{2,11}=5.07, p=.027\right)$. Again, only the effects of the 2.5 and 0.625 doses differed. The huge $42 \pm 10 \%$ increase in power/min corresponded to only an $11 \pm 4 \%$ increase in integrated amplitude per min. Period amplitude analysis shows that the elevation in $20-30 \mathrm{~Hz}$ activity was entirely due to the $11 \pm 2 \%$ increase in amplitude, as incidence did not change $(0 \pm 2 \%)$.

Waking EEG was largely unaffected by CPPene (Figure 4). Only $10-20 \mathrm{~Hz}$ power/min in post drug $\mathrm{h} 1-6$ was significantly decreased by more than one dose. The
$16 \pm 4 \%$ decrease in power $/ \mathrm{min}$ caused by $2.5 \mathrm{mg} / \mathrm{kg}$ corresponded to an $18 \pm 4 \%$ decrease in integrated amplitude per minute. This decrease was almost entirely an incidence effect with time in band per min decreasing $17 \pm 3 \%$ and amplitude decreasing only $2 \pm 1 \%$. Waking delta, though slightly elevated, was not significantly affected by any dose. In waking, as in both REM and NREM sleep, $2.5 \mathrm{mg} / \mathrm{kg}$ CPPene caused a delayed elevation in $30-50 \mathrm{~Hz}$ power/min.

\section{High Dose CPPene}

In nine separate animals, 5, 10, and $20 \mathrm{mg} / \mathrm{kg}$ doses of CPPene were given to help determine the appropriate range for the dose response study. $5 \mathrm{mg} / \mathrm{kg}$ doses were given at hour 5 or 6 of the dark period, $10 \mathrm{mg} / \mathrm{kg}$ doses were given at $\mathrm{h} 4$, and $20 \mathrm{mg} / \mathrm{kg}$ doses were given at h0, dark onset. The data are limited, but some of the observations are of interest. In all rats, 10 or $20 \mathrm{mg} / \mathrm{kg}$ $\mathrm{CPPene}$ induced an extended period (up to $12 \mathrm{~h}$ ) of in- 

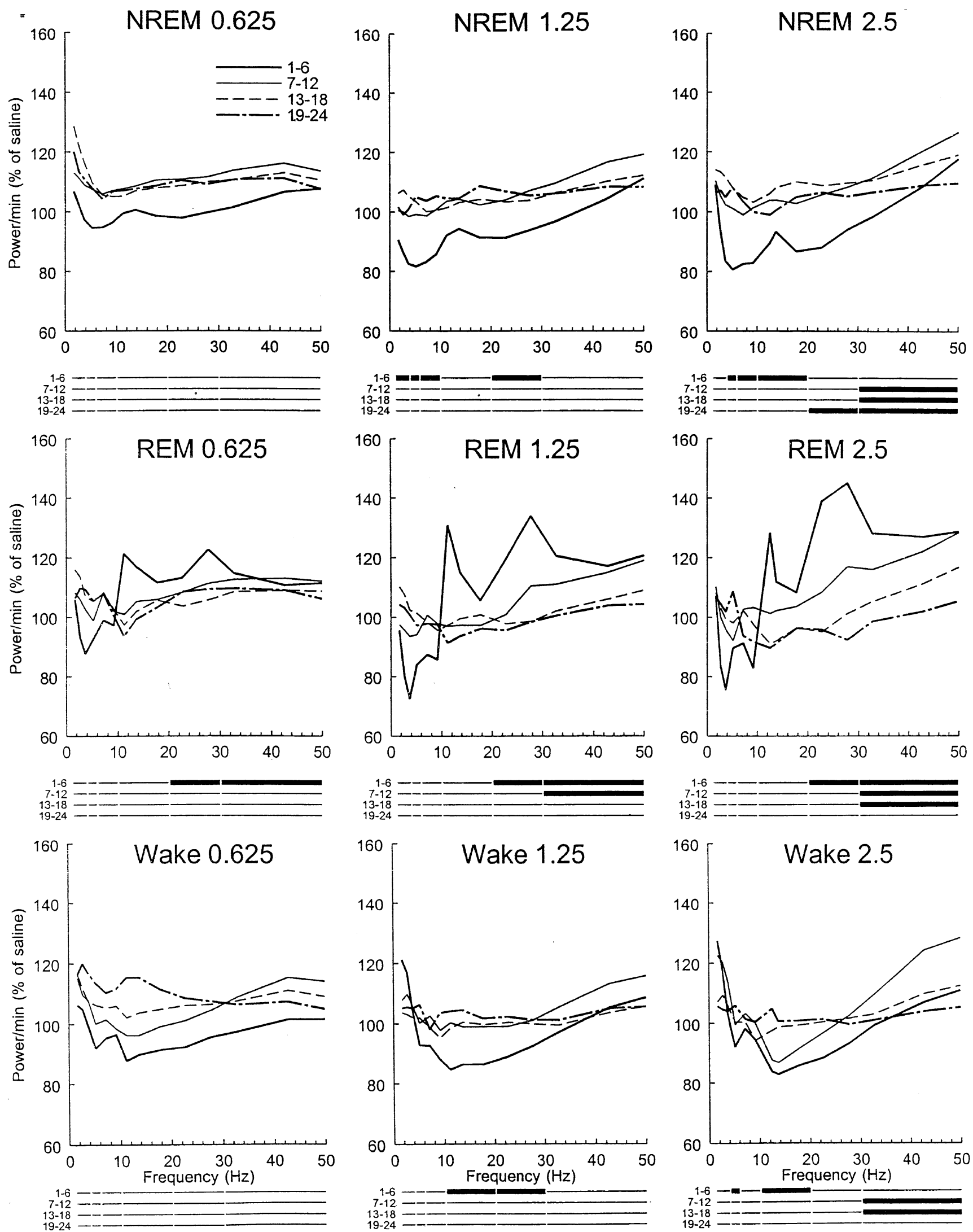

Figure 4. Time and dose response of CPPene effects on EEG power expressed as a percent of saline power in the same frequency band at the same 6-h period. For each dose and each vigilance state the four traces reflect 6-h time periods starting with 1-6 h post drug. CPPene dose dependently depressed NREM 4-10 Hz power, elevated REM 20-30 Hz power, and depressed wake $10-20 \mathrm{~Hz}$ power. The $2.5 \mathrm{mg} / \mathrm{kg}$ dose produced a delayed increase in high frequency power in all three vigilance states. Lines below each plot reflect statistical analyses for each 6-h time block for the six collapsed frequency bands. Significant $(p<.01)$ differences from saline are indicated by dark lines. 
toxication characterized by ataxia, stereotypic head wagging, circling, and hyperactivity. The EEG showed spikes and slow waves similar to those under MK-801 intoxication. NREM delta was increased post intoxication but, unlike following MK-801 intoxication, this elevation was not greater than would be expected for a similar period of sleep deprivation. A dose of $5 \mathrm{mg} / \mathrm{kg} \mathrm{CP-}$ Pene induced fragmented sleep interspersed with periods of ataxic hyperactivity. In one rat both $10 \mathrm{mg} / \mathrm{kg}$ and $20 \mathrm{mg} / \mathrm{kg}$ CPPene induced seizures with spike wave discharges in the EEG similar to those that sometimes follow systemic MK-801 (Feinberg et al. 1995). The $10 \mathrm{mg} / \mathrm{kg}$ dose induced a series of three seizures 25 to $33 \mathrm{~min}$ post injection. Durations of these seizures varied from 20 to $90 \mathrm{~s}$. The EEG spike wave discharges were accompanied by immobility with small vertical head nods.

\section{Blood Pressure}

We succeeded in recording blood pressure in two of the four rats implanted with carotid cannulas. Neither of these rats showed decreased blood pressure associated with the increased sleep following $2.5 \mathrm{mg} / \mathrm{kg}$ CPPene. Figure 5 shows delta power, rho $(25-30 \mathrm{~Hz})$ power and mean arterial blood pressure (MAP) recorded from one of these rats. Delta increased following injection as the rat spent most of the following five hours asleep. Rho peaks indicate three REM periods. MAP rose and fell with vigilance states, but never dropped below preinjection levels.

\section{DISCUSSION}

\section{Implications of CPPene Data for the Mechanism of MK-801 Stimulation of NREM Delta EEG}

CPPene, a competitive NMDA antagonist, significantly increased NREM sleep and produced a near significant increase in REM sleep in the six hours following systemic injection. However, CPPene did not increase NREM delta intensity (power/min). This is in striking contrast to the delayed massive increase in NREM delta intensity that follows systemic injection of MK-801. For example, mid-dark period injections of $0.5 \mathrm{mg} / \mathrm{kg}$ MK801 increase NREM integrated amplitude per minute by $111 \%$ in the last three hours of the dark period and by $40 \%$ over the subsequent 12 -h light period (Campbell and Feinberg 1996a).

The different delta sleep responses to CPPene and MK-801 are consistent with the proposition of our homeostatic model that the requirement for NREM delta is proportional to the waking metabolic rate of plastic brain structures. As noted above, systemic injection of MK-801 stimulates metabolism of limbic structures, but systemic CPPene does not (Boddeke et al. 1992). While

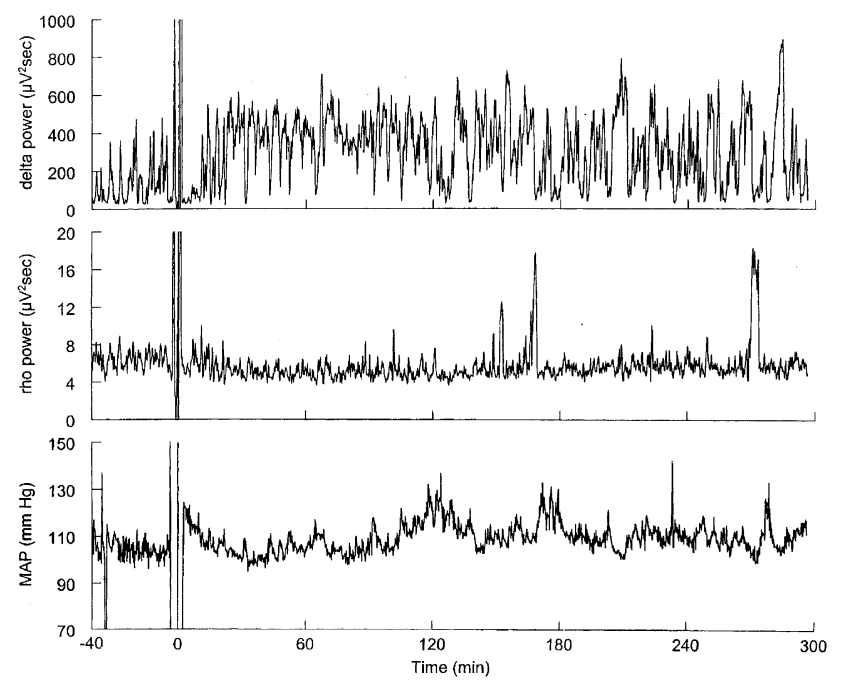

Figure 5. Delta EEG power, rho (25-30 Hz) EEG power and mean arterial blood pressure in $10 \mathrm{~s}$ epochs recorded from a restrained rat before and after injection of $2.5 \mathrm{mg} / \mathrm{kg}$ CPPene (time 0 ). EEG traces are smoothed with a 30 -s running average. CPPene induced NREM sleep as indicated by the high delta power post drug. Rho power peaks indicate REM sleep episodes. Mean arterial blood pressure changed with vigilance state, but never dropped below predrug levels.

consistent with the metabolic hypothesis of the homeostatic model, our results with CPPene do not prove it. Competitive and noncompetitive NMDA antagonists do share important anticonvulsant (cf. Smith et al. 1993) and antiexcitotoxic (cf. Hargreaves et al. 1994) actions as well as causing similar behavioral effects such as stereotypy, ataxia, and hyperlocomotion (Willets et al. 1990; Smith et al. 1993). However, these two classes of antagonists differ in ways other than their effects on limbic metabolism. For example, there are strong dose differences in the antiexcitotoxic and behavioral effects (De Sarro and De Sarro 1993; Lowe et al. 1994) and differences in operant behavior (Willets et al. 1990). It, therefore, remains possible that the different NREM delta effects are produced by differences in brain actions other than those on regional metabolism.

There are several caveats that should be considered. One is the possibility that the difference in sleep EEG response to CPPene and MK-801 is caused by a difference in effective dose rather than representing different biological actions. Indeed, high doses of competitive antagonists have been reported to increase limbic metabolism (Hargreaves et al. 1993). However, even the 20 $\mathrm{mg} / \mathrm{kg}$ dose we injected i.p. in our pilot studies is well below a $60 \mathrm{mg} / \mathrm{kg}$ i.v. dose of CPPene that did not alter brain metabolism (Boddeke et al. 1992). It might be argued that the 1.25 and $2.5 \mathrm{mg} / \mathrm{kg}$ CPPene doses that stimulated NREM sleep but did not increase NREM delta were simply less potent than the noncompetitive antagonist doses that strongly increased NREM delta. 
However, in our pilot experiments with high dosage (10 and $20 \mathrm{mg} / \mathrm{kg}$ ), CPPene did not stimulate NREM delta. Moreover, $25 \mathrm{mg} / \mathrm{kg}$ ketamine increased NREM delta, whereas $15 \mathrm{mg} / \mathrm{kg}$ did not affect either delta or NREM duration (Feinberg and Campbell 1993).

In summary, the following evidence strongly supports, but does not establish the homeostatic interpretation of the increase in slow wave EEG following MK801. NMDA receptor antagonists that increase brain metabolism greatly increase NREM delta following a period of intoxication, whereas an NMDA receptor antagonist that does not increase brain metabolism does not increase NREM delta intensity, although it immediately increases NREM sleep. The stimulus for increased delta intensity produced by MK-801 persists across a 12-h period of sleep deprivation (Campbell and Feinberg 1996b). The EEG responses following MK-801 intoxication (elevated NREM delta power and REM 10-20 $\mathrm{Hz}$ power) resemble those following sleep deprivation (Campbell and Feinberg 1999).

\section{CPPene Effects on Vigilance States and Behavior}

CPPene dose dependently increased NREM sleep and decreased waking in the six hours post injection. REM sleep increased by $50 \%$, but because of its typically high variability in the dark period this change did not reach significance at the $\alpha=0.01$ level. In addition to stimulating NREM sleep, CPPene caused a striking increase in estimated eating time in the first hour post injection. The sleep and eating drives seemed to compete. At times the animal fell asleep while at the food bin. These combined alterations of sleep and eating raise the question whether CPPene's effects are mediated by the hypocretin/orexin systems. Hypocretins increase vigilance as indicated by the findings that ICV injections of hypocretin increase waking in rats (Piper et al. 2000) and that deficiencies in hypocretin production cause the vigilance impairment associated with narcolepsy (Nishino et al. 2000; Thannickal et al. 2000). Hypocretins have also been implicated in the regulation of feeding where they have a stimulating effect (reviewed in Sakurai 1999). However, it is difficult to reconcile CPPene's stimulation of both sleep and eating with altered function of a hypocretin system that acts to increase waking and eating. It, therefore seems unlikely that a single action on hypocretin neurons could explain both the sleep and eating responses to CPPene.

When evaluating drugs that directly stimulate sleep, it is important to consider whether one is measuring pathological slow waves rather than the physiological delta EEG of NREM sleep. One possible source of pathological delta is decreased cerebral blood flow caused by systemic blood pressure changes (Feinberg and Campbell 1999). The integrity of the cerebral circulation is strongly protected and only massive changes in systemic blood pressure will alter cerebral perfusion. Such massive changes were effectively ruled out by our experiment although blood pressure was recorded in only two animals.

\section{CPPene Effects on EEG}

CPPene produced complex state-specific effects on the EEG in the first six hours post drug. NREM low frequency power decreased. Waking mid-frequency power decreased. REM high frequency power increased. The NREM and wake low and mid-frequency power decreases resulted primarily from decreased wave incidence. In contrast, increased REM high frequency power was entirely due to increased wave amplitude. Changes in wave amplitude are thought to reflect changes in summed potential changes in large neuronal populations. Changes in wave incidence are presumed to result from changes in the frequency of a central oscillator or of more localized EEG thalamocortical circuits. It is increasingly recognized that spectral analysis cannot distinguish amplitude and incidence effects and that this distinction is biologically important (Amzica and Steriade 1998; Dijk 1999). EEG waves are generated by complex cortico-thalamic interactions (Steriade et al. 1993). The CPPene effects on EEG demonstrate that these interactions can be differentially altered in different vigilance states.

CPPene increased NREM sleep in the absence of an increased homeostatic need caused by increased waking duration or brain metabolism. One might expect such excess sleep to be less intense as indicated by lower levels of NREM delta. Such a response was observed here. $1.25 \mathrm{mg} / \mathrm{kg}$ CPPene significantly decreased delta $(1-4 \mathrm{~Hz})$ power $/ \mathrm{min} .2 .5 \mathrm{mg} / \mathrm{kg}$ CPPene decreased power in 3-4 Hz (but $1-3 \mathrm{~Hz}$ power was roughly at baseline levels). Had significant recuperation occurred in the NREM sleep stimulated by CPPene, homeostatic models predict a subsequent decrease in NREM sleep. The absence of such a decrease suggests that little recuperation occurred in the CPPene-stimulated NREM sleep.

CPPene caused a delayed (by $6 \mathrm{~h}$ ) increase above control levels in high frequency EEG in all three vigilance states. The delay suggests that this increase is a response to initial changes induced by the drug. Increased high frequency EEG normally indicates increased arousal level. The delayed increase in high frequency EEG we recorded may be a rebound increase in arousal in response to any small amount of recuperation provided by the initial increase in sleep time.

\section{Glutamate and Sleep and Clinical Implications}

The data presented here add to a growing literature that glutamate plays a significant role in sleep regula- 
tion. Glutamate plays a key role in a neuronal detoxification model of sleep (Inoue et al. 1995). Earlier studies found that systemic or brain injections of glutamate receptor antagonists increased sleep (Armstrong-James and Fox 1988; Stutzmann et al. 1988; Juhasz et al. 1990) and that agonists decreased sleep (Milasius et al. 1990). More recently, Ferraro et al. (1999) proposed an inhibitory GABA/glutamate interaction in the medial preoptic area, and Azuma et al. (1996) showed that glutamate levels in the medial preoptic area of rats vary with vigilance state, increasing across waking and peaking at the onset of NREM sleep. Also, NMDA injections into the basal forebrain increase waking (Manfridi et al. 1999; Cape and Jones 2000). Our findings with CPPene contradict the finding of Stone et al. (1992) that light period injections of the competitive NMDA antagonist NPC 12626 impaired REM sleep at doses from 1 to $100 \mathrm{mg} / \mathrm{kg}$ and decreased NREM sleep at doses $50 \mathrm{mg} / \mathrm{kg}$ or greater. Although they do not present behavioral observations, we suspect that the high doses $(>50 \mathrm{mg} / \mathrm{kg})$ caused the intoxication syndrome we observed with high dose $(10$ and $20 \mathrm{mg} / \mathrm{kg}$ ) CPPene. The absence of NREM stimulation by low doses of NPC 12626 may be due to injections of the drug during the light period when NREM sleep is already high. However, we cannot explain why NPC 12626 impaired rather than increased REM sleep.

Involvement of glutamate in sleep regulation has potential clinical relevance. Current hypnotics in clinical use are GABAergic compounds that act to enhance inhibitory neurotransmission. Central nervous system inhibition and excitation work in tandem. It is, therefore, possible that sleep promoting effects similar or possibly superior to those of GABAergic hypnotics could be created by dampening excitatory neurotransmission. The short term increase in NREM sleep demonstrated here for a competitive NMDA antagonist supports this possibility and should encourage further exploration of drugs that modulate excitatory neurotransmission for hypnotic and other therapeutic (anxiolytic) actions.

\section{ACKNOWLEDGMENTS}

We wish to thank Tara Montgomery and Anh Nguyen for expert technical assistance with vigilance state scoring. PHS grants R01MH50741 and R01MH57928 and the Research Service of the Department of Veterans Affairs supported this research.

\section{REFERENCES}

Amzica F, Steriade M (1998): Electrophysiological correlates of sleep delta waves. Electroenceph Clin Neurophysiol 107:69-83
Armstrong-James M, Fox K (1988): Evidence for a specific role for cortical NMDA receptors in slow-wave sleep. Brain Res 451:189-196

Azuma S, Kodama T, Honda K, Inoue S (1996): State-dependent changes of extracellular glutamate in the medial preoptic area in freely behaving rats. Neurosci Lett 214:179-182

Boddeke HWGM, Wiederhold KH, Palacios JM (1992): Intracerebroventricular application of competitive and non-competitive NMDA antagonists induce similar effects upon rat hippocampal electroncephalogram and local cerebral glucose utilization. Brain Res 585:177-183

Borbely A (1982): A two-process model of sleep regulation. Hum Neurobiol 1:195-204

Campbell IG, Feinberg I (1993): A cortical EEG frequency with a REM-specific increase in amplitude. J Neurophysiol 69:1368-1371

Campbell IG, Feinberg I (1996a): Noncompetitive NMDA channel blockade during waking intensely stimulates NREM delta. J Pharmacol Exp Ther 276:737-742

Campbell IG, Feinberg I (1996b): NREM delta stimulation following MK-801 is a response of sleep systems. J Neurophysiol 76:3714-3720

Campbell IG, Feinberg I (1999): Comparison of MK-801 and sleep deprivation effects on NREM, REM, and waking spectra in the rat. Sleep 22:423-432

Cape EG, Jones BE (2000): Effects of glutamate agonist versus procaine microinjections into the basal forebrain cholinergic cell area upon gamma and theta EEG activity and sleep-wake state. Eur J Neurosci 12:2166-2184

Crosby G, Crane AM, Sokoloff L (1982): Local changes in cerebral glucose utilization during ketamine anesthesia. Anesthesiol 56:437-443

De Sarro GB, De Sarro A (1993): Anitconvulsant properties of non-competitive antagonists of the N-methyl-D-aspartate receptor in genetically epilepsy-prone rats: comparison with CPPene. Neuropharmacol 32:51-58

Dijk DJ (1999): Circadian variation of EEG power spectra in NREM and REM sleep in humans: Dissociation from body temperature. Sleep Res 8:189-195

Dixon WJ, Brown MB, Engelman L, Jennrich RI (1990): BMDP Statistical Software Manual. Berkeley, CA, University of California Press

Feinberg I (1974): Changes in sleep cycle patterns with age. J Psychiat Res 10:283-306

Feinberg I, Campbell IG (1993): Ketamine administration during waking increases delta EEG intensity in rat sleep. Neuropsychopharmacology 9:41-48

Feinberg I, Campbell IG (1995): Stimulation of NREM delta EEG by ketamine administration during waking: demonstration of dose-dependence. Neuropsychopharmacology 12(1):89-90

Feinberg I, Campbell IG (1999): Adenosine, blood pressure and NREM delta. Sleep 22:7-9

Feinberg I, Campbell IG, Marrs JC (1995): Intraperitoneal dizocilpine induces cortical spike-wave seizure discharges in rats. Neurosci Lett 196:157-160

Ferraro L, Antonelli T, Tanganelli S, O'Connor WT, Perez de la Mora M, Mendez-Franco J, Rambert FA, Fuxe K 
(1999): The vigilance promoting drug modafinil increases extracellular glutamate levels in the medial preoptic area and the posterior hypothalamus of the conscious rat: prevention by local GABAA receptor blockade. Neuropsychopharmacology 20:346-356

Hammer RP, Herkenham M (1983): Altered metabolic activity in the cerebral cortex of rats exposed to ketamine. J Comp Neurol 220:396-404

Hargreaves RJ, Rigby M, Smith D, Hill RG, Iversen LL (1993): Competitive as well as uncompetitive N-methylD-aspartate receptor antagonists affect cortical neuronal morphology and cerebral glucose metabolism. Neurochem Res 18:1263-1269

Hargreaves RJ, Hill RG, Iversen LL (1994): Neuroprotective NMDA antagonists: the controversy over their potential for adverse effects on cortical neuronal morphology. Acta Neurochir 60:15-19

Inoue S, Honda K, Komoda Y (1995): Sleep as neuronal detoxification and restitution. Behav Brain Res 69:91-96

Juhasz G, Kekesi K, Emri Z, Soltesz I, Crunelli V (1990): Sleep-promoting action of excitatory amino acid antagonists: a different role for thalamic NMDA and nonNMDA receptors. Neurosci Lett 114:333-338

Kurumaji A, Nehls DG, Park CK, McCulloch J (1989): Effects of NMDA antagonists, MK-801 and CPP, upon local cerebral glucose use. Brain Res 496:268-284

Lowe DA, Emre M, Frey P, Kelly PH, Malanowski J, McAllister KH, Neijt HC, Rudeberg C, Urwyler S, White TG, Herring PL (1994): The pharmacology of SDZ EAA 494, a competitive NMDA antagonist. Neurochemistry International 25:583-600

Manfridi A, Brambilla D, Mancia M (1999): Stimulation of NMDA and AMPA receptors in the rat nucleus basalis of Meynert affects sleep. Am J Physiol 277:R1488-R1492
Milasius AM, Grinevicius KK, Lapin IP (1990): Effect of quinolinic acid on wakefulness and sleep in the rabbit. J Neural Trans 82:67-73

Nelson SR, Howard RB, Cross RS, Samson F (1980): Ketamine-induced changes in regional glucose utilization in the rat brain. Anesthesiol 52:330-334

Nishino S, Ripley B, Overeen S, Lammers GJ, Mignot E (2000): Hypocretin (orexin) deficiency in human narcolepsy. Lancet 355:39-40

Piper DC, Upton N, Smith MI, Hunter AJ (2000): The novel brain neuropeptide, orexin- $\mathrm{A}$, modulates the sleepwake cycle of rats. Eur J Neurosci 12:726-730

Sakurai T (1999): Orexins and orexin receptors: implication in feeding behavior. Regulatory Peptides 85:25-30

Smith SE, al-Zubaidy ZA, Chapman AG, Meldrum BS (1993): Excitatory amino acid antagonists, lamotrigine and BW 1003 C87 as anticonvulsants in the genetically epilepsy-prone rat. Epilepsy Res 15:101-111

Steriade M, McCormick DA, Sejnowski TJ (1993): Thalamocortical oscillations in the sleeping and aroused brain. Science 262:679-685

Stone WS, Walker DL, Gold PE (1992): Sleep deficits in rats after NMDA receptor blockade. Physiol Behav 52:609-612

Stutzmann JM, Lucas M, Blanchard JC, Laduron PM (1988): Riluzole, a glutamate antagonist, enhances slow wave and REM sleep in rats. Neurosci Lett 88:195-200

Thannickal TC, Moore RY, Nienhuis R, Ramanathan L, Gulyani S, Aldr M, Cornford M, Siegel JM (2000): Reduced number of hypocretin neurons in human narcolepsy. Neuron 27:469-474

Willets J, Balster RL, Leander JD (1990): The behavioral pharmacology of NMDA receptor antagonists. Trends Pharmacol Sci 11:423-428 